\title{
Perspective
}

\section{A Unified Approach to the Study of Mutation, from Bacteria to Humans: Some Potentialities of the New DNA Technologies}

\author{
James V. Neel ${ }^{*}$ \\ Department of Human Genetics, The University of Michigan, Ann Arbor, Michigan
}

Key words: mutations in DNA; 2-D DNA gels; standardized mutation studies; comparative mutagenesis

Let me at the outset express my deep appreciation at the receipt of the Annual Award of the Environmental Mutagen Society. In the 27 years since this Award was established, it has recognized many persons for seminal contributions to the field of mutagenesis, and I am honored to join those previous recipients. I was impressed by how many different facets of the subject of mutagenesis they represented. Today, in the course of my brief remarks, I hope to direct attention to still another aspect of our complex field.

As many of you know, for more than 50 years I have been involved in studies of spontaneous and radiation-induced mutation rates in humans. This work has been in collaboration with quite a number of American and Japanese colleagues, to whom I am very grateful and whose contributions will be recognized in the citations that follow. Now, my genetic roots were formed in the course of studies with two eminent Drosophilists, Warren P. Spencer and Curt Stern, and you can be certain that after my transition into human genetics and my involvement with the genetic effects of the atomic bombs, I have kept a close eye on developments in experimental radiation genetics, especially those involving the fruit fly and the mouse. Some 17 years ago, in the Wilhemina E. Key Lecture of the American Genetic Association [Neel, 1983], I attempted to compare spontaneous mutation rates in the fruit fly, the house mouse, and humans. It was a pretty unsatisfactory business, but what emerged was, to me, an apparent surprising similarity in the spontaneous mutation rates per gene per generation of these three species, considering the great differences in their life cycles. Then, some 9 years ago, Susan Lewis and I [Neel and Lewis, 1990] attempted to compare radiationinduced rates in humans and mice, and again it was a frustrating undertaking. Now the issue was to what extent did the genetic findings on radiation effects in humans agree with those on mice. This is a whole other story I do not propose to get into today, other than to comment that recent developments regarding mosaic mutation in mice [Russell

Published 1999 Wiley-Liss, Inc. ${ }^{\dagger}$ This article is a US Government work and, as such, is in the public domain in the United States of America. and Russell, 1996] and the prevalence of cluster mutations in mice [Selby, 1998] seem to be bringing the estimates of the genetic doubling dose based on mice closer to the higher estimate based on the findings in Japan [Neel, 1999].

But today, rather than dwelling on the past, I propose to engage in a fantasy for the future. The fantasy emerges out of the truly amazing developments in molecular genetics and genomics over the past several decades. The fantasy involves the concept that we may soon be able to study comparative mutagenesis, both spontaneous and induced, at the DNA level, thus providing the ultimate basis for acrossspecies comparisons. As I say this, I realize that many EMS members have already been engaged in analyzing at the molecular level a variety of mutations detected through some phenotypic effect. I want to talk about a method of screening for mutations that begins at the molecular level.

\section{OUR PRELIMINARY STUDIES}

Beginning in 1979, techniques for visualizing on a twodimensional gel the DNA fragments resulting from genomic digests began to become available [Fischer and Lerman, 1979; Hatada et al., 1991; Uitterlinden et al., 1989; Yi et al., 1990]. We are now well into a pilot study exploring the applicability of this approach to studying the genetic effects of the atomic bombs, employing a modified version of the technique described by Hatada et al. [1991], as further developed by Asakawa et al. [1995]. Hatada et al. [1991] have termed this technique "restriction landmark genomic scanning" (RLGS).

Annual Award address of the Environmental Mutagenesis Society, presented March 29, 1999, in Washington, DC.

Contract grant sponsor: NCI; Contract grant number: CA26803.

*Correspondence to: James V. Neel, M.D., Ph.D., Department of Human Genetics, Box 0618, M4708 Medical Science II, University of Michigan, Ann Arbor, MI 48109-0618. 
About the same time these DNA techniques began to become available, the Radiation Effects Research Foundation in Hiroshima, Japan, the Japan-USA follow-up agency on atomic bomb effects, realized that the exposed parents of the children who would be the objects of a genetic study were beginning to enter a time of high mortality, this fact greatly complicating genetic studies, and a major project to create family constellations of Epstein-Barr virus-immortalized lymphocytoid cell lines was set in motion, under the direction of Dr. Chiyoko Satoh. To date, cell lines of some 600 mother/father/child trios for which one or both parents were exposed to the atomic bomb explosions have been established, as well as another 600 control trios for which the parents were unexposed. Sometimes two or even three children of a set of parents were available. This is the material which the above-mentioned study is employing.

Figure 1 is of a gel based on one of these lymphocytoid cell lines. For a diploid organism such as our species, in the absence of sex-linkage or genetic variation, each spot on the gel is the product of two homologous DNA fragments (other than the large spots due to repetitive sequences). For these preparations, genomic DNA was digested with the NotI and EcoRV restriction enzymes and the NotI derived 5' protruding ends were $\alpha-{ }^{32} \mathrm{P}$ labeled. These fragments were electrophoretically separated in an agarose disc gel, which was subsequently treated with HinfI to further cleave the fragments in situ. The resulting fragments were separated perpendicularly in a $5.25 \%$ polyacrylamide gel $(33 \times 46 \times$ $0.05 \mathrm{~cm}$ ). Autoradiograms were then obtained [Asakawa et al., 1994, 1995; Kuick et al., 1995]. NotI cut sites are most commonly found in the $\mathrm{CpG}$-rich islands that are relatively frequent near or in functional genes; we would expect gels such as this to have a much heavier representation of fragments from functional genes than a random sample of DNA.

The visual comparison of the gel of a child with those of its parents, to detect attributes of a child's gel not present in either parent, i.e., a potential mutation, would be extremely demanding, the type of activity guaranteed to lead to a high turn-over rate in technicians. Fortunately, a computer algorithm we had earlier developed for the analysis of protein gels [Skolnick and Neel, 1986] proved suitable, with considerable modification, for the analysis of these complex DNA images [Asakawa et al., 1994]. Among the approximately 2,000 DNA fragments to be visualized on one of these preparations, we identified a subset of approximately 500 for which the coefficient of variation (CV) of spot intensity was $\leq 0.12$, this reproducibility permitting the distinction between spots of normal intensity and spots with $50 \%$ intensity with high accuracy (i.e., two-fragment or one-fragment spots). A child in whom a given spot was 50\% normal intensity, whereas both parents exhibited $100 \%$ intensity, would represent a mutation. Some $15 \%$ of these fragments have been shown to exhibit mendelizing genetic variation. We believe that with impending technical developments, the battery of fragments suitable for quantitative scoring may increase to 600 or 700 per gel. Other enzyme combinations can be used for the genomic digests that precede the gel runs and, by altering the electrophoretic conditions, larger DNA fragments can be visualized. Currently we are working on three different types of gels for which we believe there is little overlap in the DNA fragments visualized. Furthermore, we have demonstrated the feasibility of recovering (and characterizing the nucleotide sequence of) specific DNA fragments from the gels [Asakawa et al., 1994]. Thus, a mutant fragment can be precisely studied. Some 30 of these spots have already been characterized in detail. We presume that in time the nucleotide sequences of all the DNA fragments being scored in any given type of gel will be established and, given as a result of the Genome Project complete DNA sequences for various species, the across-species comparisons can involve homologous types of DNA. Up to the present time, there has been no mutation detection system that would detect all possible types of mutation. This system is no exception. It should primarily detect mutations leading to insertions/ deletions/rearrangements. It would also detect nucleotide substitutions that either eliminated an enzyme cleavage site or created a new such site.

Our long-time colleagues in Japan, Dr. J. Asakawa and Dr. N. Nakamura, have in progress a study on the ability of this system to detect an increase in mutation in the offspring of irradiated mice [Asakawa et al., 1998a,b]. Figure 2 illustrates one of the types of mouse gels in use in their study. Without going into detail, I can say that the system has detected mutations, including several that occurred as a cluster, the clusters occurring in the offspring of both the controls and the treated series. In these animal experiments, it is not necessary to go through the labor of establishing cell lines; one can work with fresh tissues.

\section{EXTENSION OF THE METHODOLOGY TO OTHER SPECIES}

Mice and humans are relatively easy subjects for this type of study, because their size simplifies the recovery of DNA. What about our two other favorite objects for studies of spontaneous and induced mutation rates, the fruit fly and E. coli? For Drosophila, the chief issue, because of the small size of the fly, would be to devise a breeding scheme that would expand the DNA from single offspring of treated or untreated flies to suffice for this type of examination. For $E$. coli, on the other hand, given the ease with which individual bacteria are cloned, resulting in enormous numbers of offspring, there should be no problem in obtaining sufficient DNA for analyses of this type.

\section{COMPARISON OF SOMATIC CELL AND GERM CELL MUTATION RATES}

For many years now, the desirability of somatic cell indicators of genetic damage has been obvious, and several 


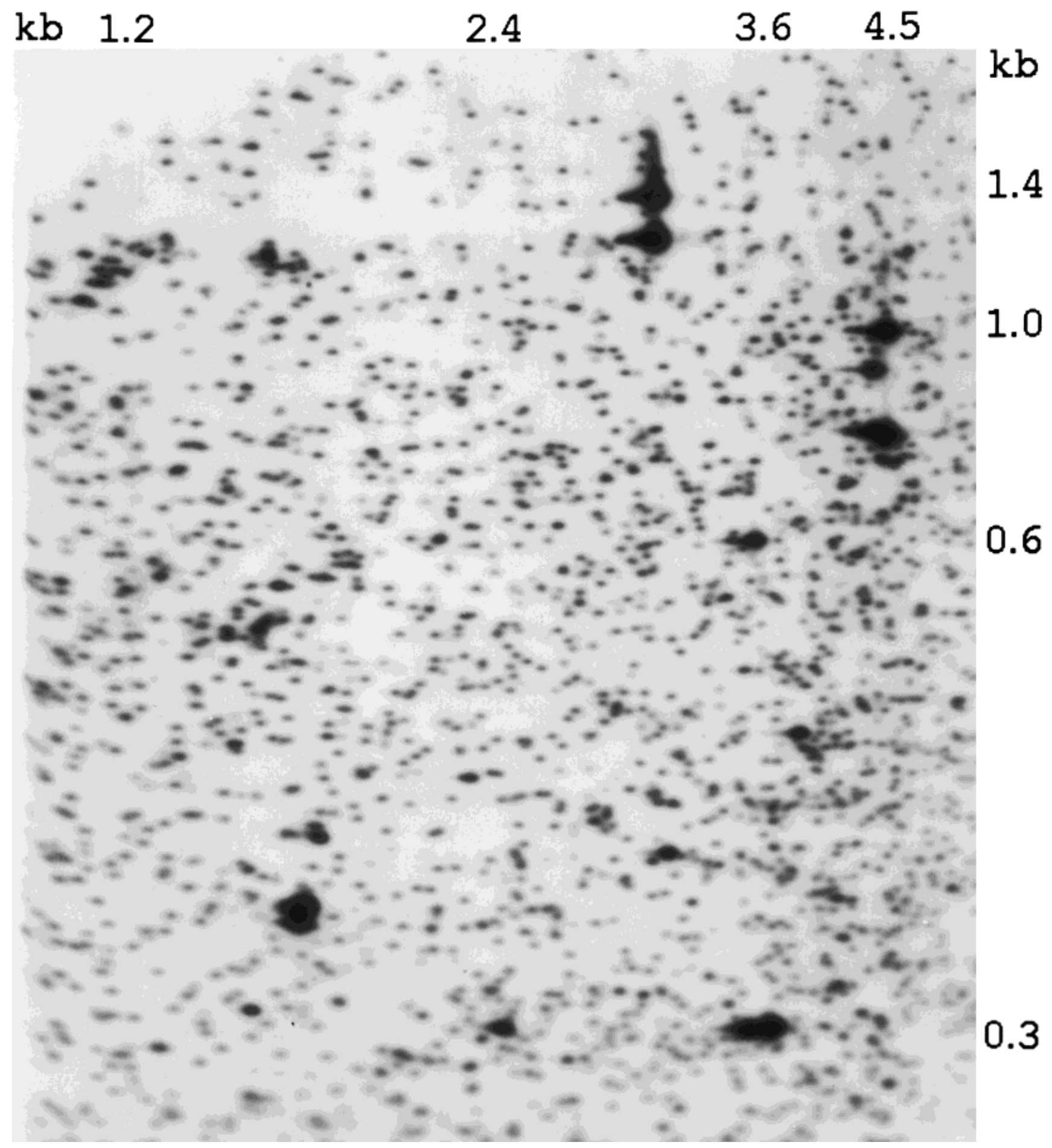

Fig. 1. A computer-processed image of a two-dimensional DNA gel prepared from an E-B virus transformed lymphocytoid cell line.

possible systems have been explored. Four such systems deserve mention: 1) cytogenetic damage in cultured lymphocytes; 2) mutations in the glycophorin system; 3) mutations in the HGPRT system; and 4) mutant T lymphocytes defective in the expression of the T-cell antigen receptor gene. Each of these systems has been shown to provide evidence of radiation effects, but each has its limitations as a barometer of germ-line damage. For each of these indicators, there is the question of how well it represents the genome as a whole. For these and other reasons, the investigators working with these systems have been properly cautious in suggesting doubling dose estimates, albeit these 


\section{kbp 1.0}

\section{$\longleftarrow$ Notl + EcoRV Mouse} 5.0

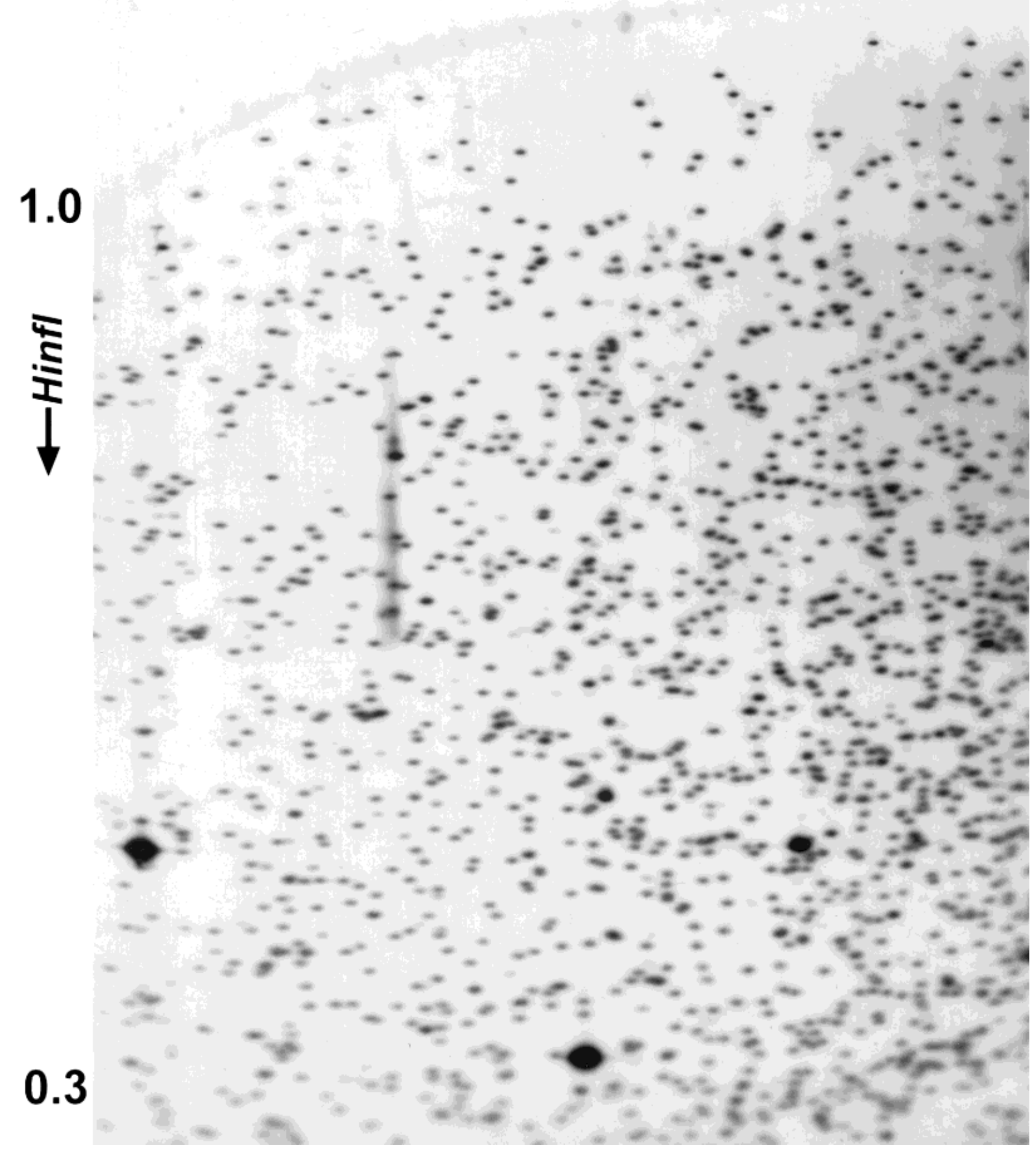

Fig. 2. A computer-processed image of a two-dimensional DNA gel prepared from DNA extracted from a mouse spleen. Preparation courtesy of Dr. J. Asakawa. 


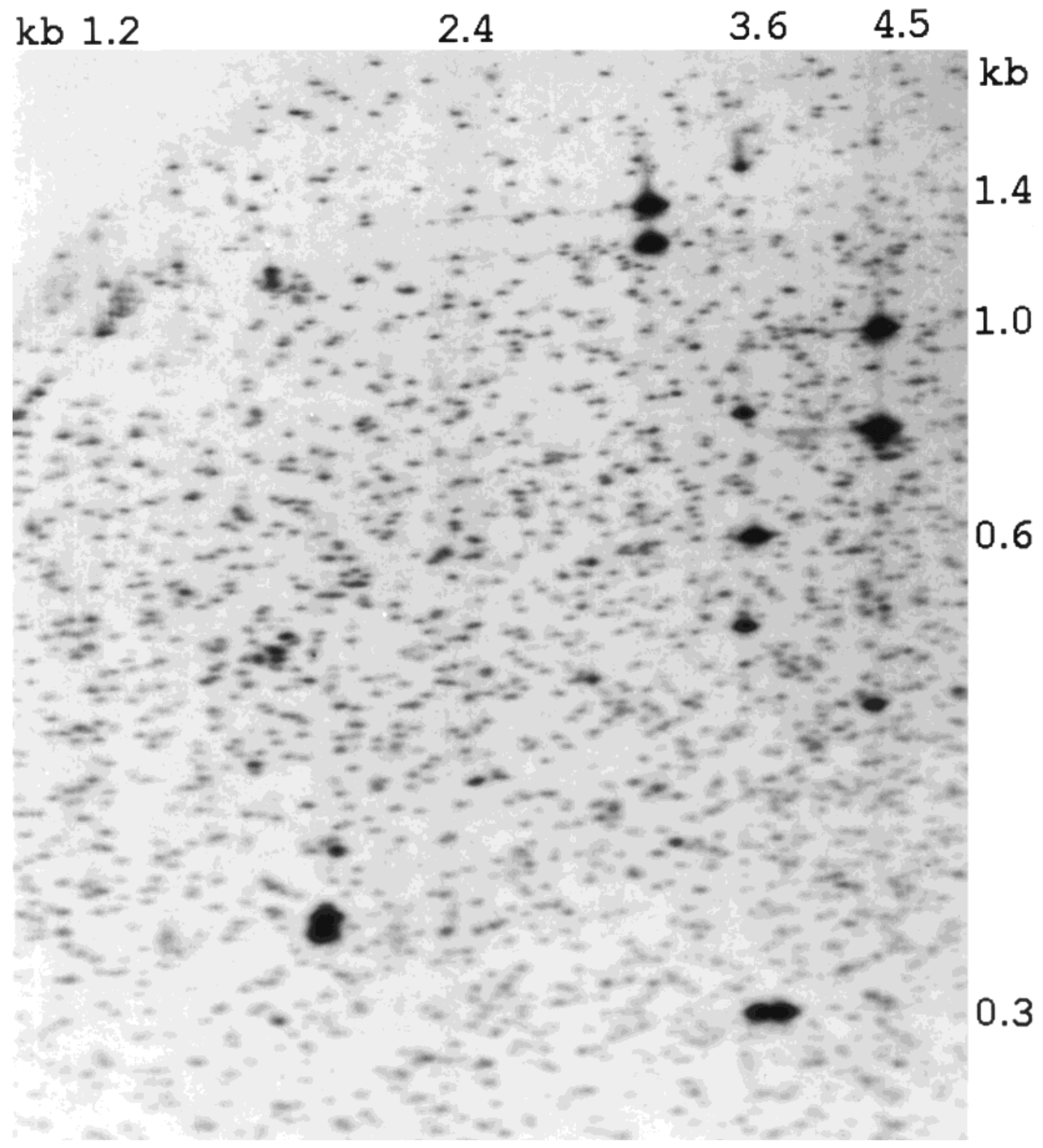

Fig. 3. A computer-processed image of a two-dimensional DNA gel prepared from a cell line developed from a single transformed peripheral lymphocyte.

are the types of estimates needed for comparison with germinal rates and for guidelines regarding permissible exposures.

I would like to suggest a fresh approach to the matter of spontaneous and induced somatic cell mutation. Figure 3 is based on a 2-D DNA preparation from an individually and directly cloned B lymphocyte transformed by the EpsteinBarr virus, prepared in the Ann Arbor laboratory by Dr. Samir Hanash's group. The detailed similarity to the preparation based on the Japanese cell lines is striking. Although 
our studies are still preliminary, we suggest that this technique may represent a new and powerful multi-locus approach to the study of spontaneous and induced somatic cell mutation, the technique having the additional advantage that the results of a somatic cell study on a group sustaining a mutagenic exposure would be directly comparable to the results of a study of cell lines from their children that used the same technique.

\section{THE CHIP}

The methodology I have suggested for across-species comparisons of mutation rates in DNA is of course only one of several that might be developed in the future. At the moment, great interest centers around the various versions of what is commonly called "the chip." The chip is a very dense array of DNA oligonucleotides - now as many as 400,000 distinct oligonucleotides, each precisely positioned in its own $20 \times 20 \mu \mathrm{m}^{2}$ region and anchored to an appropriate base - against which one can test an unknown sample for identity. Failure to obtain complete hybridization of an appropriate test sample with a standard would indicate a variant. One might also design a chip as a gene sequencing machine. A recent supplement to Nature Genetics is the most orderly presentation of this complex subject I have seen [Phimister, 1999]. In addition to this treatment, I refer you to five recent articles more specifically discussing the detection of mutations [Drobyshev et al., 1997; Ginot, 1997; Gunderson et al., 1998; Hacia, 1999; Pinkel et al., 1998]. The term mutation as employed by the authors of these articles refers to all genetic variants (including polymorphisms) rather than freshly arisen mutations.

These chip approaches to the detection of mutation are basically still all on the drawing board, and it is impossible to compare them at this time with other methodologies. In principal, the approach should detect all types of mutations at any locus (or other specified DNA sample) for which a standard DNA sequence has been established. In this respect, it is clearly superior to the RLGS method, which will fail to detect nucleotide substitutions which do not alter enzyme cleavage sites (most such substitutions), as well as DNA rearrangements involving only a few nucleotides and hence not altering spot position to a degree the analytic algorithm will detect.

The potential of this system is obvious; unfortunately, so is the cost. Each chip might be designed to scan a specific gene. The cost of such a chip would be justified in a medical diagnostic setting. However, for a study of rare mutational events, one would have to employ chips specific for hundreds of genes per individual, as well as corresponding chips for both parents. If instead of studying specific genes one used the chip as a sequencing device for carefully chosen DNA sequences, the cost of detecting a mutation might be somewhat reduced. But, at the moment, the chip technology would appear to be an expensive way to study mutation, to be used only on very special populations. One such population might be the above-mentioned Japanese groups for whom cell lines are already available, for which the individual radiation exposures remain among the best characterized and highest of all the various radiationexposed populations in the world.

\section{PRACTICAL AND SCIENTIFIC FRUITS OF THIS APPROACH}

The practical implications in the realization of an RLGS system (and its possible successors) seem obvious. Assuming the identity of the various DNA fragments being studied is established, at long last we will have a measure which permits accurate across-species comparisons of mutation rates, spontaneous and induced. As for the science, while I have presented this fantasy primarily in terms of its contributions to genetic monitoring and studies of comparative mutagenesis, there is an even more basic aspect. Evolution is driven by mutation and formal treatments of evolution are liberally sprinkled with the symbol $\mu$, the usual symbol for mutation. As one who has frequently struggled with these formulations, I can speak with feeling to the leap of faith involved in assigning a particular value to $\mu$ in a given situation. With actual DNA-based values, these treatments should proceed with greater confidence. Furthermore, it is by now very obvious that all mutations are not equal in the eyes of selection. Insertion/deletion/rearrangement events must be considered in a very different light from simple nucleotide substitutions, and their impacts on evolution treated separately.

In closing, I thank you again for the honor of this Award, and for permitting me to share this particular fantasy with you. Considered in light of the many frustrations of the past in arriving at reliable across-species comparisons of mutation rates, it does indeed today seem to be a fantasy. On the other hand, considered in light of the almost unbelievable cascade of genetic techniques and discoveries during this century, it is perhaps not completely unrealistic to expect developments of this sort during the next century.

\section{ACKNOWLEDGMENT}

I thank Mr. Rork Kuick for helpful discussions of the chip.

\section{REFERENCES}

Asakawa J, Kuick R, Neel JV, Kodaira M, Satoh C, Hanash SM. 1994. Genetic variation detected by quantitative analysis of end-labeled genomic DNA fragments. Proc Natl Acad Sci USA 91:9052-9056.

Asakawa J, Kuick R, Neel JV, Kodaira M, Satoh C, Hanash SM. 1995. Quantitative and qualitative genetic variation in two-dimensional DNA gels of human lymphocytoid cell lines. Electrophoresis 16: 241-252.

Asakawa J, Kodaira M, Katayama H, Funamoto S, Tomita S, Itoh M, 
Preston D, Nakamura N. 1998a. Detection of spontaneous and $\mathrm{X}$-ray induced germ cell mutations in mice by computer assisted two-dimensional DNA gel analysis. Abstract presented at the 1998 Annual Meeting of the Japan Radiation Research Society.

Asakawa J, Kodaira M, Katayama H, Funamoto S, Tomita S, Itoh M, Preston D, Nakamura N. 1998b. Study of spontaneous and X-ray induced germ cell mutations in mice detected by computer assisted two-dimensional DNA gel analysis. Abstract presented at the 1998 Annual Meeting of the Japan Radiation Research Society.

Drobyshev A, Mologina N, Shik V, Pobedimskaya D, Yershov G, Mirzabekov A. 1997. Sequence analysis by hybridization with oligonucleotide microchip: identification of $\beta$-thalassemia mutations. Gene 188:45-52.

Fischer SG, Lerman LS. 1979. Length-independent separation of DNA restriction fragments in two-dimensional gel electrophoresis. Cell 16:191-200.

Ginot F. 1997. Oligonucleotide micro-arrays for identification of unknown mutations: How far from reality? Hum Mutat 10:1-10.

Gunderson KL, Huang XC, Morris MS, Lipshutz RJ, Lockhart DJ, Chee MS. 1998. Mutation detection by ligation to complete $n$-mer DNA arrays. Genome Res 8:1142-1153.

Hacia JG. 1999. Resequencing and mutational analysis using oligonucleotide microarrays. Nat Genet 21(Suppl 1):42-47.

Hatada I, Hayashizaki Y, Hirotsune S, Komatsubara H, Mukai T. 1991. A genomic scanning method for higher organisms using restriction sites as landmarks. Proc Natl Acad Sci USA 88:9523-9527.

Kuick R, Asakawa J, Neel JV, Satoh C, Hanash SM. 1995. High yield of restriction fragment length polymorphisms in two-dimensional separations of human genomic DNA. Genomics 25:345-353.

Neel JV. 1983. Frequency of spontaneous and induced "point" mutations in higher eukaryotes. J Hered 74:2-15.
Neel JV. 1999. Changing perspectives on the genetic doubling dose of ionizing radiation for humans, mice, and Drosophila. Teratology $53: 216-221$.

Neel JV, Lewis SE. 1990. The comparative radiation genetics of humans and mice. Annu Rev Genet 24:327-362.

Phimister B, editor. 1999. Review: chipping forecast. Nat Genet 21:1-60.

Pinkel D, Segraves R, Sudar D, Clark S, Poole I, Kowbel D, Collins C, Kuo W-L, Chen C, Zhai Y, Dairkee SH, Ljung B, Gray JW, Albertson DG. 1998. High resolution analysis of DNA copy number variation using comparative genomic hybridization to microarrays. Nat Genet 20:207-211.

Russell LB, Russell WL. 1996. Spontaneous mutations recovered as mosaics in the mouse specific-locus test. Proc Natl Acad Sci USA 93:13072-13077.

Selby PB. 1998. Major impacts of gonadal mosaicism on hereditary risk estimation, origin of hereditary diseases, and evolution. Genetica 102/103:445-462.

Skolnick MM, Neel JV. 1986. An algorithm for comparing two-dimensional electrophoretic gels, with particular reference to the study of mutation. In: Harris H, Hirschhorn K, Harris H, Hirschhorn KS. Advances in human genetics. New York: Plenum Press. p 55-160.

Uitterlinden AG, Slagboom PE, Knook DL, Vijg J. 1989. Two-dimensional DNA fingerprinting of human individuals. Proc Natl Acad Sci USA 86:2742-2746.

Yi M, Au LC, Ichikawa N, Ts'o PO. 1990. Enhanced resolution of DNA restriction fragments: a procedure by two-dimensional electrophoresis and double labeling. Proc Natl Acad Sci USA 87:3919-3923.

Accepted byT. A. Cebula 